\title{
COMMON CORE/DIVERSITY DILEMMA, AGATHEISM AND THE EPISTEMOLOGY OF RELIGIOUS BELIEF
}

\section{THOMAS D. SENOR}

\author{
University of Arkansas
}

The essay "The Common-Core/Diversity Dilemma: Revisions of Humean Thought, New Empirical Research, and the Limits of Rational Religious Belief" is a bold argument for the irrationality of "first-order" religious belief (that is, the belief that adherents to particular religions have). However, unlike those associated with "New Atheism," the paper's authors Branden Thornhill-Miller and Peter Millican claim both that there are prospects for rational "second-order" religious belief (a religion-neutral belief in a designer of some sort) and that religious belief and practice can play a positive role in human life. In response to Thornhill-Miller and Millican, Janusz Salamon has argued that firstorder religious belief can be rational, although not via the methods that philosophers who have typically defended the reasonability of faith have appealed to. Both papers are fascinating discussions of the epistemology of religious belief in general, and of the rationality of such commitment in light of modern science and religious disagreement in particular. In this paper, I'll object to a few points made in each essay and argue that neither paper provides good reason to be dubious about the religious belief being rational along traditional lines.

\section{THORNHILL-MILLER AND MILLICAN'S DILEMMA}

Thornhill-Miller and Millican (hereafter TMM) argue that what they call the "Common Core/Diversity Dilemma" shows that first-order religious beliefs are irrational. That is, the standard religious beliefs of the practioners of all the various theological traditions are not rationally held. But it doesn't follow from this, they claim, that there might not be some rational religious belief. So called "second-order" religious belief is essentially the deistic conviction that there is a designer, full stop. 
The ground of such belief, they aver, is the fine-tuning argument. Because the universe is fine-tuned for life, and it is argued by some, the best explanation for such fine tuning is that the universe is designed for life, one might rationally conclude that although all first-order religious claims (or nearly all of them at any rate) are irrational, one might rationally believe in an abstract designer.

It seems to me that the argument that TMM give for the irrationality of first-order religious belief can be objected to at several points. Furthermore, I'll maintain that even if their argument were sound, one could still reasonably hold out hope for a more robust rational religious belief than what they think is possible. To begin, let's have a look at their main argument.

A key claim TMM argue for is what they call the "Common Core/ Diversity Dilemma."

That in so far as religious phenomena (e.g., miracle reports, religious experiences, or other apparent perceptions of supernatural agency) point towards specific aspects of particular religions, their diversity and mutual opposition undermines their evidential force; while in so far as such phenomena involve a 'common core' of similarity, they point towards a proximate common cause for these phenomena that is natural rather than supernatural (p. 3).

Although not a traditional dilemma, the apparent problem is this: any phenomenon that seems to evidentially support a distinctive claim of a particular religion is undermined by the fact that there are other similar phenomena that would seem to evidentially support distinctive claims of other religions (i.e,. claims of other religions that are inconsistent with the claim being supported by the first-mentioned phenomenon). On the other hand, those phenomena that might be thought to support claims that all religious traditions have in common are best explained by proximate natural causes. So to put the point in the form of a dilemma, we get this:

P1. Every purported religious experience is either (i) religion specific (that is, taken to support a distinctive claim of a particular religion) or (ii) religion general (that is, taken to be part of a common core of experience had by participants of various religious traditions).

$\mathrm{P} 2$. If a purported religious experience $\mathrm{E}$ is religion specific, its epistemic efficacy is undermined by the fact that there are experiences 
had by those in other religious traditions that equally support claims incompatible with the religion specific claim that $\mathrm{E}$ supports.

$\mathrm{P} 3$. If a purported experience $\mathrm{E}$ is religion general, then its epistemic efficacy is undermined by the fact that there is a proximate cause of $\mathrm{E}$ that is natural rather than supernatural.

C1. Therefore, the epistemic efficacy of every purported religious experience is undermined (i.e., no religious experience makes religious belief rational).

A few words are in order about this argument as I've stated it. I mean "religious experience" to be meant in a rather broad sense so that it includes all that TMM include in their characterization of "religious phenomena" - that is, miracle reports, religious experiences, or other apparent perceptions of supernatural agency. Also, when TMM say that the "diversity and mutual opposition of religion specific phenomena undermines their evidential force," I take them to mean that the prima facie rational support that such religious phenomena provide are epistemically defeated by the fact that there are other equally tenable experiences that support incompatible religious claims. So it is consistent with their dilemma that these experiences themselves provide some evidential support but that the support is undermined by the competing experiences.

While I believe the argument as I've stated it accurately portrays the dilemma that PMM mean to defend in their essay, the conclusion they reach in their essay is considerably stronger than the conclusion I've stated in C1. For the argument as I've constructed it is perfectly consistent with first-order religious belief (again, that's belief in any particular religious tradition) being epistemically rational or justified. The conclusion that their dilemma supports is only that religious phenomena of the type PMM have characterized does not provide ultima facie rational support for first-order religious belief. Yet their argument is clearly meant to say that there are no grounds of any kind for rational first-order religious belief. And to get that conclusion we have to add an additional premise. This, I take it, is how the argument ends.

$\mathrm{P} 4$. The only rational ground for first-order religious belief is religious experience.

C2. Therefore, first-order religious belief is not rational. 


\section{EVALUATING THORNHILL-MILLER AND MILLICAN'S DILEMMA}

The argument as stated is valid so if one doesn't accept the conclusion, one will have to reject a premise. So let's consider the argument a premise at a time.

With one proviso, I'm willing to accept P1. One might understand "religion specific" as meaning unique to a particular religion. So a Roman Catholic's vision of Mary would be a clear enough instance of a religion specific experience in this first sense: it's an experience that might provide rational support for Roman Catholicism but that won't for other religious traditions. But if this is how we are to understand "religion specific" then the disjunction of P1 is clearly not exhaustive. For there can be experiences that support more than one religious tradition without supporting all of them. One who has an experience of God as personal will thereby have some prima facie rational support for any of the theistic traditions but will not have such support for pantheistic religions. So there are really three kinds of relevant experience: that which prima facie supports a single religion, that which prima facie supports multiple religions but not all religions, and that which prima facie supports all religions (i.e., the common core). I propose to understand "religion specific" to cover the first two sorts of experience. As long as that which an experience supports is inconsistent with a religious tradition, it falls under the "religious specific" category. ${ }^{1}$ With this understood, I take P1 to propose an exhaustive dichotomy.

P2 is also initially problematic. The mere fact that there are others who have experiences that support religious beliefs inconsistent with the one's own does nothing to undermine the prima facie rationality provided by one's experience. When religious communities are epistemically isolated from each other, their competing, inconsistent beliefs may well be mutually rational. So P2 will have to be understood not as claiming that the mere fact that there is "diversity and mutual opposition" of religion specific experiences undermines rational support; rather, the problem comes when individuals from each community know of, or at least believe, that such a diversity exists.

So understood, is P2 plausible? Well, it certainly bears a striking resemblance to a point often made in the literature on epistemic

${ }^{1}$ TMM never discuss just what they take to constitute a religion or whether everything that one might count as a religion should be taken to be on an epistemic par with all others. 
disagreement: if I have an experience that leads me to believe that $\mathrm{P}$ and I know that you have an experience that leads you to believe $\sim$, and I have no more reason to think my experience is trustworthy than I have for thinking yours is trustworthy, then if I continue to believe $\mathrm{P}$ with the same conviction I had prior to knowing about your experience and belief, then I'm irrational. Consider David Christensen's case of people dividing a dining tab. ${ }^{2}$ Several people have dinner and agree to split the tab evenly. Two of the diners do the math but come up with different results. On the assumption that each takes the other to be equally good at such calculations, both should withhold belief once the disagreement comes to light. The question of interest in the present context concerns the degree to which members of different religious communities have no more reason to trust their experiences than they do the experiences of those in other communities.

A case can be made for thinking that members of a community may have more reason to trust their experiences than they have for trusting the experiences and resultant beliefs of others. For one thing, people have much more experience with their traditions and with other members of their religious community. On the assumption that the people they know are generally reliable and well-intended, they will have greater reason to trust what they have to say than they will have to trust those with whom they are unfamiliar. This will be true particularly in cases in which the communities are mostly separated and when members of the various communities know little about each other.

P2 also assumes a general parity among the practioners of various religions regarding the experiences they have and the beliefs they form on the basis of them. But that is, of course, an empirical matter for which TMM offer no evidence.

So I think that P2 is rather too broad and makes an unsupported empirical assumption. Still, I'm prepared to acknowledge that the more one learns about the diversity and depth of religious experience among various world religions, the more one has reason to question the veracity of the religion specific beliefs so formed. And while no evidence has been marshalled for the parity assumption, I'm prepared to grant it (at least regarding the main world religions). We could reword P2 so that it explicitly states that it is the known "diversity and mutual opposition" of experience and belief that undermines the prima facie rationality

${ }^{2}$ Cf. Christensen 2007. 
of the respective beliefs, but for brevity's sake, I'll leave it as stated but understand it with this emandation.

P3 asserts that the primafacie rationality of religion general experiential beliefs is defeated because recent research strongly suggests that such experiences and the beliefs based on them have natural, proximate causes. That there are natural proximate causes of religious experience isn't particularly surprising nor is it obvious how this fact impinges on questions of epistemic rationality. Among the data that TMM cite and discuss have to do with meditative and introvertive religious experience, near death experiences, our hypersensitivity to perceiving agency in nature, and egocentric and confirmation bias. This is a diverse group of topics and I certainly don't have the space to engage with the literature here. But others have had a good deal to say about the cognitive science of religious belief and experience that TMM do not address. And many of these authors take a far less skeptic view the matter. ${ }^{3}$ But since I'm not presenting arguments against TMM's skeptical understanding of the data, I'll draw no conclusions here about the plausibility of this premise.

In order to get TMM's final conclusion, we had to add $\mathrm{P} 4$ which says that religious belief can be rational only if it is grounded in experience. Given the history of natural theology in the philosophy of religion, it surprising that TMM apparently think that only experientially-based reasons can make first-order religious belief rational. Why might they think that? We get a clue in the following passage:

But such a position [i.e., second-order theism] will fail to satisfy the vast majority of believers, including even those philosophers who (like F.R. Tenant, Basil Mitchell, and Richard Swinburne) aim to establish their theism on the basis of a 'cumulative case' that supplements the theistic arguments with an appeal to historical records and contemporary experience as providing evidence of specific supernatural intervention in human history. ${ }^{4}$

So TMM apparently think that the standard theistic arguments taken by themselves will not be sufficient to make first-order religious beliefs (that is, beliefs that are specific to particular religions) rational; in order for beliefs of the Christian, Jew, Muslim, Buddhist, Hindu, etc., to be rational, there will have to be experiences and resultant beliefs that are

\footnotetext{
${ }^{3}$ See Barrett and Church 2013, Clark and Barrett 2011, and Schloss and Murray 2009.

4 Thornhill-Miller \& Millican, 2015, p. 4.
} 
specific to those traditions. And those religion specific beliefs will need to be justified via "historical records and contemporary experience."

With two significant caveats, I will provisionally grant this claim. Consider, for example, the case of Christianity. Even if a priori arguments were sufficient for establishing or at least rationally grounding generic theism, it would seem that Christians' belief that Jesus Christ was God incarnate who performed miracles and who rose from the dead is grounded, at least originally, in the experience of those who witnessed the life of Christ and who believed they experienced him post resurrection of Jesus. Still, I suppose this isn't strictly speaking necessary: it could have happened that Jesus (or any other religious figure) lived in obscurity (if at all) and that at a later time someone had an experience that she took to be a supernatural message about the life, works, and significance of Jesus. But even in such a case, it seems as though the original grounding of these claims (assuming they aren't simply knowingly made up by a charlatan) would come from religious experience - that is, from an experience that the person who has it takes to be supernatural.

Be all of that as it may be, I have two caveats. First, although perhaps in order for a specific religion to get off the ground (as it were) there will need to be experiences that are taken to be supernatural, such experiences are not generally necessary for a person to have religion specific beliefs. The most common means of coming to have religious belief is via the testimony. Whether such testimony is the proselytizing of strangers or the lessons that one learns in one's church, mosque, synagogue or other place of religious practice, a standard way in which religious beliefs are passed on is not through experience that people take to be supernatural, but rather through what one is told by others (and, of course, sometimes it is a combination of the two). The fact that religious belief not only can be but often is grounded in testimony is significant because testimony is standardly taken to be a rationality conferring process. Of course, the matter is complicated and not all forms of testimony are on an epistemic par with one another. But if it is generally rational to base beliefs on testimony, then it could well provide rational support for religious beliefs, and so P4 would turn out to be false.

There is a catch, however. Given the claim that I'm willing grant provisionally - namely, that specific religions generally require some alleged supernatural experience at least for the purpose of getting established - an important question now is this: if a contemporary believer bases her belief on testimony, is it necessary that the beliefs of the testifier 
trace back some way or other to a purported supernatural experience? If so, then testimony will not be a means for belief to be rational if TMM's dilemma is right. While as with pretty much any philosophical issue, there are competing views regarding the epistemology of testimony. But a standard perspective is that where rationality is concerned, there need not be unbroken chains of justification. That is, a testifier might not be rational in her belief, but sincerely assert that $\mathrm{P}$ and a hearer might thereby come to rationally believe that P. So, even if TMM's argument might cause problems for the rationality of specific religions in a general, person-neutral sense, many believers might be rational in their beliefs.

Now for the second caveat: if the teleological reliabilism of Alvin Plantinga's Reformed Epistemology is right, then the grounding of one's belief neither needs to be experiential itself nor even trace back to anything experiential. In fact, one needn't accept Plantinga's particular form of reliabilism: any kind of purely externalist theory will entail that what makes a belief epistemically acceptable doesn't have to do with anything experiential; rationality (or at least justification or warrant) has to do with having that are reliably connected to the world. But to stick for the moment with Plantinga's position, what will make any belief warranted ultimately is not that it is derived from our experience but because it is the product of a properly functioning, reliable, truth-aimed belief forming process operating in an appropriate environment. On Plantinga's view, any proposition at all can be warranted provided that those conditions are met. Furthermore, while Plantinga often talks of mundane religious experience when he gives examples (e.g., that upon seeing a sunset behind a mountain peak one might come to believe that there is a benevolent creator), the condition that must be satisfied for warrant makes no reference to anything the subject experiences. That is, the content of the experience isn't what generates the warrant of the belief; it is the belief's being formed by a properly functioning, truthaimed, reliable process operating in the appropriate environment.

To sum up our discussion of the dilemma: we've seen reason to think that each premise is problematic as it is stated. By my lights, the main problems with the dilemma are the following: (i) while the fact that there are competing experiences and beliefs among major religions, it is not clear that this fact alone serves to defeat the prima facie rationality that religious experiences provide, even when this disagreement is generally known; (ii) the epistemic impact of the findings of the cognitive and 
social sciences pertinent to the religion general experiences is far from clear; the fact that there are naturalistic proximate causes doesn't imply that such experiences are not veridical; and (iii) even if there are problems with the rationality of beliefs base on alleged supernatural experience, religion specific beliefs can, for all TMM have argued, be rational either via testimony or because externalism is true.

Before concluding, there is one other point worth mentioning. TMM maintain that their dilemma leaves only what they call "second-order" religious beliefs as potentially rational since both religion specific and religion neutral beliefs and experiences are defeated. And second-order religious belief of the sort they specify is, as they recognize, essentially just deism. The world has been brought about by a designer who wanted it to produce life, but who is otherwise unknowable and is not involved in the operation of the universe. ${ }^{5}$ But absent a careful critique of the standard arguments for the existence of God, this surely isn't a conclusion they are in a position to draw.

Let's consider the ontological argument. It purports to show that there exists a being than which nothing greater is possible. Plausibly, if such a being exists it is a personal, omnipotent, omniscient, omnibenevolent being who is not only the ground of our existence but is also the fount of morality. Even if all of this is true, no specific claims of any particular theistic religion follows. But the deistic deity of TMM's secondorder religion is far surpassed. An Anselmian God is a being that is fundamentally worthy of worship and service, and to whom one would be drawn to pray.

Many are (reasonably) suspicious of all varieties of ontological argument. But the standard cumulative case arguments, while not providing reason for any particular religious tradition, give one much better reason to accept a full-blown theism as opposed to a minimal deism. Combining strands from the cosmological argument, the design argument (including the fine-tuning argument), and the argument from morality, the cumulative case argument also stands a chance of providing rational support for an extremely powerful designer who is the ground of morality. Again, this falls short of a defense of any first-order religion but the content is much richer than the extremely thin second-order religion described by TMM.

${ }^{5}$ TMM equate second-order theism with deism on page 4 at the beginning of the first full paragraph. 


\section{SALAMON'S AGATHEISM}

In his fascinating essay, Janusz Salamon paints a somewhat rosier picture of the prospects of rational first-order religious belief. According to Salamon, religious belief should be looked at most fundamentally as axiologically grounded and as "identifying the Ultimate Reality religiously conceived with the ultimate good which is postulated as a transcendental condition of our axiological consciousness through which we perceive and evaluate the goods at which our actions are aimed and towards which our hopes are directed."' Salamon's idea (which he calls "agatheism") is that the fundamental religious inspiration is a sense that there is an ultimate good that transcends the physical world, and hence will forever remain unexplained by the sciences. By itself, this will give us a more substantial concept of the Ultimate Reality than the sparse deism imagined by TMM, but it will be quite a bit thinner a notion than the traditional theism of classical Western theism. But from this starting place, different traditions will fill out their worldviews in different ways, holding fast the conviction that the deepest (or highest) truth about the deity is its ultimate goodness which underlies our axiological consciousness. Salamon thinks that as long as the doctrines of particular religions do not conflict with what we know to be true from the sciences, then if they are internally coherent, they are sufficiently rational. One might even speak of religious certainty, although it must be kept in mind that religious certainty is more like moral certainty than it is like the kind of certainty on aspires to in science; the latter is objective whereas the former is subjective. Finally, a virtue of agatheism, as Salamon sees it, is that it allows for diverse first-order religious traditions to be rational inasmuch as they are all on an epistemic par (where they are consistent with the undisputed findings of science).

So much for my quick, and undoubtedly unsatisfactory, overview of what I take to be Salamon's main position. One thing that Salamon and TMM agree on is that standard arguments for the existence of God are unhelpful when it comes to the rational acceptability of religious belief. Salamon address this point more straightforwardly than TMM do so I want to have a look at what his reasons are for being skeptical of their epistemic force. I'll conclude by arguing there are reasons to be dubious of the ecumenical conclusion that Salamon thinks agatheism confers on the rationality of first-order religious beliefs.

${ }^{6}$ Salamon 2015, p. 201. 
Salamon thinks that he has an a priori argument against the success of the arguments of natural theology. He writes:

To begin with, one can argue a priori against the availability of proofs or conclusive arguments regarding God's existence, since the very concept of such proof or conclusive argument appears to be incoherent, as by definition God transcends human concepts, hence what is being grasped in human concepts which are applied to God cannot be God as God really is. Therefore the theistic arguments may at most serve as 'pointers' ... or 'paths' ... that may direct human thought towards God, without reaching God, because the concept of God itself - involving such qualifications as 'perfect' or 'infinite' - stipulates that God as God as really is, is out of reach of the human mind. Only divine mind can grasp God, thus argument for the existence of the referent of a human concept of God, one cannot conclusively establish the existence of God."7

There are, I think, two big problems with the argument in this paragraph. First, our inability to construct an argument for God's existence doesn't follow from the fact that God "transcends human concepts" unless one means more by "God transcends human concepts" than Western theists have generally meant. The fact humans lack the conceptual wherewithal to fully understand the divine nature doesn't show that they are incapable of providing decent arguments that there exists a being with some of the attributes traditionally applied uniquely to God. Given how extremely complex and mind-boggling the physical world is turning at to be, it is altogether possible that humans aren't capable of fully understanding it; but it doesn't follow that we can't provide arguments for its existence and that it has some of the properties it has.

The second big problem with Salamon's argument against natural theology is the assumption that if there are no proofs or conclusive arguments for God's existence, then the best one can hope is for them is to serve as 'pointers' or 'paths' (whatever precisely those metaphors mean in this context). But at least since 1967 with the publication of Alvin Plantinga's influential book God and Other Minds, philosophers of religion haven't expected, even in the very best of cases, for the theological arguments to have the epistemic weight of conclusive proofs (which can be understood as logically valid arguments the premises of which are compelling to any rational person). ${ }^{8}$ And it isn't as though natural

\footnotetext{
7 Salamon 2015, p. 208.

${ }^{8}$ Cf. Plantinga 1967.
} 
theology is unusual in this respect: outside of mathematics, conclusive proofs are rare. In the absence of such knock-down arguments, there is still the possibility of an argument's providing good reason or evidence for its conclusion. Contemporary philosophers who defend the arguments of natural theology (e.g., Richard Swinburne and William Lane Craig) take themselves to be offering strong although inductive reason for believing in the God of traditional theism (and, in the case of Swinburne and Craig, even for historical Christianity).

Salamon thinks the case against a posteriori (or "empirical") arguments for God's existence is even easier to make since "there is no way one could deduce from finite effects the existence of an infinite Divine cause." (But again, there is a huge chasm between deduction on the one hand, and merely pointing on the other. And while the principle that a finite effect will never entail an infinite cause seems right, that's not the claim of the natural theologian. One way to think of the matter is like this: theistic traditions posit an aspatial, atemporal, omnipotent, morally good infinite creator. The natural theologian might then appeal to the Big Bang and say that science teaches that there was a first moment of our universe and the best explanation for that is that there is a non-natural cause; because prior to the Big Bang, there was no space or time, the cause might be aspatial and atemporal; because of the vastness of the universe, the cause must be extremely powerful; because of fine-tuning, the cause must be intelligent; because humans have a clear sense of morality and value, and yet these seem to be non-natural (i.e., not the kind of phenomena that science will ever be able to study), their source must be non-natural. In short, there is a broad range of phenomena that are better explained by the theistic hypothesis than they are by naturalism. Therefore, there is a strong inference to the best explanation for theism.

My purpose here is not to defend the claim that there are good a priori or a posteriori arguments for God's existence. My point instead is that quick, transcendental arguments of the kind that Salamon offers fail to provide an adequate ground for rejecting them in one fell swoop. If I am right about this, then Salamon's claim that the only way in principle to ground theistic belief is "by reasoning from human axiological consciousness" 10 is mistaken.

\footnotetext{
${ }^{9}$ Salamon 2015, p. 208.

10 Salamon 2015, p. 211.
} 
Having argued that natural theology cannot be the rational ground of religious belief, Salamon then argues that first-order religion can yet be epistemically in the clear in virtue of a kind of "justificatory descent" from the main agatheistic claim that the Ultimate Reality is ultimate goodness. From this proposition, believers might think that God is the source of all that exists or that God will reveal himself since he will want what is best for us. Exactly how these inferences go and the way the concept of the divine and its relation to us is filled out will be different from religious traditional to religious tradition. And these beliefs will be rational not because of any kind of argument from natural theology but rather because the primary agathestic insight is justified and given the experience of the believers in their particular traditions, the more particular beliefs will have a kind of conditional rationality. Yet since the relationship of the more specific religious claims is a pointing to the Ultimate Reality rather than a deduction from a first principle, the first-order believer will not take her first-order claims as anything like scientifically-confirmed truth. Hence the various traditions should look with interest and appreciation of perspectives that differ from theirs, since they are all, in a deep sense, doing the same thing: pointing to the Ultimate Reality as best they can.

I think Salamon's perspective is deeply interesting and, in many ways, attractive. It is very hard to look at the great religions of the world and not think that there is a common reality to which they are all attempting to point. I'm also significantly drawn to the idea that one can be a rational, full participant in a particular religious tradition even while one recognizes that there are other, incompatible religious traditions with fully rational participants.

Despite its attractiveness, the perspective that Salamon is offering doesn't strike me as a picture of how, for example, Christians, Jews, Muslims, Buddhists, and Hindus can all be rational in the differing beliefs that they actually hold. Rather, I think Salamon's conception is revisionary. That is, I would find it plausible if the right way to think about first-order religious believers were as follows: instead of holding their competing religious doctrines as true, the faithful were to genuinely believe in a good Ultimate Reality and then think something like "the lens that I prefer to see the Ultimate through is A, but I recognize that what one sees depends on the lens one uses, and so the lenses B, C, D, $\mathrm{E}$, and $\mathrm{F}$ of other traditions offer different, but equally valid views of 
the Ultimate." But I don't think this is how most of the faithful think about their specific religious beliefs. Rather, I take them to genuinely believe not only that "God is good" is true, but that, e.g., when Christians affirm that "God was in Christ reconciling the world to himself" and Muslims believe "Muhammad is God's final prophet" they don't typically think that these are essentially metaphors or equally accurate ways of describing God's relation to the world.

If I am right about that, then even if something like justificatory descent from the primary agatheistic belief occurs, the convictions that it generates are genuine beliefs. And if that's right, they have truth-values, and beliefs that are logically inconsistent with them cannot be true if they are. So if I know that others have beliefs that are inconsistent with my religious beliefs, and if I have no reason to think my tradition is epistemically superior to the traditions of others, then rationality would seem to require that I have less confidence in my beliefs than I would have. Although I'd like to draw a different conclusion in such cases, it is hard to see how competing perspectives don't reduce the rationally of one's belief at least to a degree.

\section{CONCLUSION}

The essays by TMM and Salamon are important and interesting contributions to the epistemology of religious belief. While TMM are considerably more skeptical than Salamon is, both sides are to be commended for engaging in this discussion with a spirit that is simultaneously true to their convictions while taking seriously, and even empathetically, the position of their intellectual opponents. I hope that this conversation is only beginning. 